NOTA

CRÍTICA

\section{POLITIQUE ÉCONOMIQUE}

\section{Agnès Bénassy-Quéré et al.}

De Boeck Supérieur, París, 4édition, 2017.

\section{Politique économique}

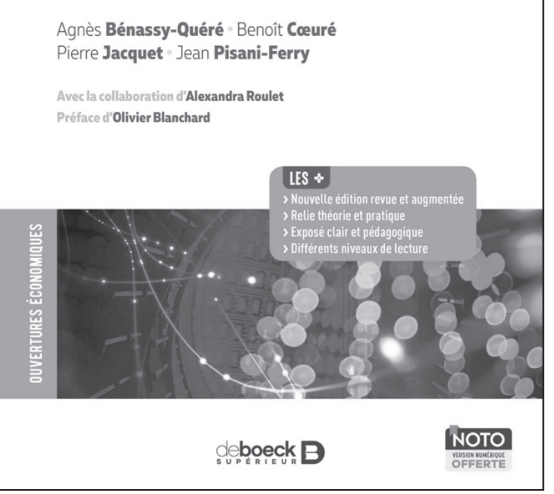

La lectura de los manuales al uso, en la década de los sesenta y setenta del siglo pasado, solían alimentar el optimismo sobre la capacidad de la política económica para alcanzar un crecimiento estable con pleno empleo. Para muestra basta un botón. En la primera edición, publicada en 1972, del popular texto de Branson, Macroeconomic: Theory and Poli$c y$, se podía leer lo siguiente: «la macroeconomía moderna se ha desarrollado como un marco analítico para entender qué origina las grandes y a veces prolongadas fluctuaciones en el nivel de empleo... nos ha enseñado bastante bien cómo conservar el pleno empleo». Después de varias décadas y distintas crisis económicas y financieras los economistas somos conscientes de las limitaciones y posibilidades de la política económica. De hecho, como se afirma en el libro objeto de esta reseña, «a partir de los ochenta, la investigación económica ha abordado de forma sistemática todas las deficiencias de la aproximación tradicional de la política económica, señalando sus límites teóricos y empíricos».

Politique Économique se editó por primera vez en 2004. Desde entonces se han publicado versiones en inglés, italiano y chino $\mathrm{y}$, hace pocos meses, está disponible su cuarta edición en francés. En ese intervalo de tiempo el libro se ha ido modificando según evolucionaban los acontecimientos $\mathrm{y}$, especialmente, después de la crisis financiera de 2008-2009 y del euro en 2010. Sus autores son profesores que realizan o han realizado labores de asesoramiento para la toma de decisiones políticas al más alto nivel lo que les ha permitido lograr un equilibrio, que no es habitual, entre teoría y práctica. Se trata, en definitiva, de un excelente manual de política económica, escrito con rigor, que posee distintos niveles de lectura, incluyendo recuadros en los que, con frecuencia, se formalizan algebraicamente las ideas, y que aborda con objetividad las discusiones, tanto a nivel académico como político, sobre las respuestas que deberían tener los problemas económicos que estamos padeciendo.

Los tres primeros capítulos presentan el marco general. En el primero se justifica la necesidad de la política económica para alcanzar los objetivos en el ámbito de la asignación, la estabilización y la redistribución, y se exponen los principales métodos y análisis para su correcta evaluación.

El segundo capítulo es especialmente interesante porque sintetiza, de manera ordenada, las principales limitaciones que posee la visión tradicional de la política económica $\mathrm{y}$, por consiguiente, las posibilidades que tiene en la actualidad. La visión tradicional de la política económica suponía la existencia de un Gobierno omnisciente, omnipotente y benevolente que podía alcanzar la estabilidad económica, eligiendo los instrumentos precisos para lograr los objetivos que se habían fijado. Esta visión tan cándida es cuestionada ante las siguientes limitaciones: existe desconocimiento sobre la estructura de la economía y, en consecuencia, sobre la manera más adecuada de modelizarla; los agentes no se comportan pasivamente ante las acciones de las autoridades públicas, sino que las anticipan y diseñan sus propias estrategias, lo que dificulta tanto la 
evaluación de las políticas como su propia eficacia; el incumplimiento de las medidas anunciadas afecta a la credibilidad de la política económica y, por tanto, a su capacidad para lograr los resultados esperados; la información no es perfecta y se distribuye de forma desigual entre los distintos actores, lo que promueve comportamientos no deseados; por último, los dirigentes políticos no siempre persiguen el interés general sino que poseen sus propias funciones de utilidad y son sensibles a las preferencias de los lobbies o de determinados sectores o grupos sociales. Ahora bien, como señalan los autores, el hecho de que se reconozcan todas esas limitaciones no implica que se ponga una «fe excesiva» en las virtudes de la autorregulación de los mercados y, paralelamente, se subestime el papel de la política económica.

El tercer capítulo, que cierra los dedicados al marco en el que se desenvuelve la política económica, añade una nueva crítica a la concepción tradicional de la intervención pública. La creciente interdependencia entre países y entre distintos niveles de gobierno ha superado la visión de un único decisor que ejerce plenamente el poder. Paralelamente, la presencia de bienes públicos globales, como la preservación del clima o de la estabilidad financiera, y los efectos internacionales que tienen determinadas medidas que toman los países individualmente, harían aconsejable la coordinación de las políticas económicas. Los autores dejan claro que esa coordinación tiene sus límites e inconvenientes y que, en determinados casos, puede que una coordinación parcial sea peor que la ausencia total de coordinación. Las alusiones a la Unión Europea, no solo en este capítulo, sino en el libro en general, son frecuentes. Sobre esa base, se plantea de una manera ecuánime el debate entre los federalistas, que desean dotar de más competencia a la Unión Europea, y los antifederalistas, cuyo objetivo es descentralizar las decisiones. No obstante, algún lector quizás hubiera deseado una visión crítica del fenómeno de la globalización, un término que, por cierto, solo se encuentra mencionado en algunas referencias bibliográficas.

El resto de la obra analiza las políticas con un esquema común: cuestiones, teorías y políticas. Así, el capítulo cuarto se dedica a la política fiscal (politique budgétaire) que tiene un tratamiento diferenciado de la política impositiva (politique fiscale) y que se analiza en un capítulo posterior. La importancia que han adquirido los temas relacionados con la sostenibilidad de la deuda pública o con la necesidad de estabilización presupuestaria en la eurozona, en el contexto del Pacto de Estabilidad y Crecimiento, han hecho que la política fiscal adquiera un especial protagonismo en el diseño de la política coyuntural. Los autores, después de repasar algunos conceptos básicos y exponer ciertas cuestiones teóricas y empíricas que rodean a la política, llegan a la conclusión de que, igual que ocurre con la política económica en general, las circunstancias macroeconómicas concretas determinarán el papel que debería tener la política fiscal para estabilizar la economía. En particular, si las fluctuaciones económicas son amplias y sincronizadas internacionalmente, los tipos reales de interés son negativos, y la deflación es una amenaza cierta, entonces la política fiscal expansiva puede ser eficaz e, incluso, tener un efecto positivo sobre la inversión privada. En caso contrario, su capacidad para estabilizar la economía sería limitada y la prioridad sería el equilibrio de las finanzas públicas a largo plazo.

Por otro lado, es muy significativa la definición que se hace de la política monetaria en el capítulo cinco: "consiste en administrar la cantidad y los precios de la liquidez, es decir de los medios de pago, para alcanzar uno o varios objetivos: la estabilidad de precios, el pleno empleo, o, según el régimen de cambio, la estabilidad del tipo de cambio». Se reconoce, por tanto, como una herramienta para la estabilización económica general y no solo de los precios. En cualquier caso, los autores no tardan en afirmar 
que «está generalmente admitida» la hipótesis de la neutralidad del dinero a largo plazo, esto es, la ausencia de efectos permanentes de la oferta monetaria sobre las variables reales de la economía. A continuación, se tratan, a nivel teórico, aspectos tales como las rigideces a corto plazo, la tasa de interés óptima, la credibilidad de los bancos centrales, o los canales de transmisión de la política monetaria y su relación con la política fiscal. A nivel práctico se abordan, en primer término, los aspectos institucionales relacionados con la independencia de los bancos centrales y su reputación («hacer lo que se dice y decir lo que se hace») prestando especial atención al estatus, mandatos y responsabilidad de los cuatro principales bancos centrales del mundo (la Reserva Federal americana, el Banco Central Europeo, el Banco de Inglaterra, y el Banco de Japón). A partir de ahí, se responden las preguntas claves relacionadas con la ejecución de la política monetaria: ¿cuál es el objetivo de inflación? ¿qué estrategia monetaria implementar? ¿debe vigilarse el precio de los activos (incluidos los inmobiliarios)? El capítulo termina insistiendo en la importancia de la estabilidad del sistema financiero para garantizar la eficacia de la política monetaria.

Precisamente, el capítulo seis se ocupa de la estabilidad financiera. Es una de las novedades de esta edición y una señal del esfuerzo que han realizado los autores por revisar y poner al día su obra. De entrada, se presenta una breve historia de las finanzas, se definen ciertas técnicas e instrumentos financieros, como la titulación de activos, y se explica cómo las crisis financieras pueden crecer hasta convertirse en crisis sistémicas. Las referencias a la crisis financiera mundial que se desencadenó a partir de agosto de 2007 son inevitables. También se explica el funcionamiento del mercado de capitales, incluyendo algunos modelos analíticos, y el papel de los bancos en la gestión del riesgo. Otros temas más específicos, como la teoría del seguro o del ahorro para la jubilación, son obviados. En cambio, el lector podrá encontrar un tratamiento claro y conciso de las causas que pueden provocar la aparición y propagación del riesgo sistémico y de las políticas que promueven la estabilidad financiera. Aquí surgen las políticas macroprudenciales que, básicamente, pretenden reforzar la solvencia de los bancos ante los riesgos de carácter sistémico. Lo cierto es que este tipo de políticas son relativamente recientes por lo que, a diferencia de lo que ocurre, por ejemplo, con la política monetaria, no poseen un marco analítico claro. Por esta razón resulta meritorio la inclusión de epígrafes que definen sus objetivos e instrumentos. No obstante, a pesar de la entrada en vigor de normas que reglamentan y supervisan a los bancos y a los mercados de capitales, se admite que sería ilusorio pensar que no volverá a aparecer otra crisis financiera.

La política de tipo de cambio junto con los asuntos concernientes al sistema monetario internacional se aborda en el capítulo siete. Las cuestiones teóricas toman como referencia el trilema de Mundell. Solo se pueden alcanzar dos de estas tres opciones: perfecta movilidad de capitales, tipos de cambios fijos, y política monetaria independiente. En el sistema de Bretton Woods, con un sistema de tipos de cambios fijos, o se establecían controles de capitales o se supeditaba la política monetaria al mantenimiento del tipo de cambio. A partir de la década de los noventa del siglo pasado, con la creciente liberalización de los movimientos de capitales y el desarrollo de los mercados financieros, los países con políticas monetarias orientadas al logro de objetivos internos renunciaron a fijar su tipo de cambio. Dentro de la eurozona la lógica se hace más evidente y los países carecen de una política monetaria propia. En este contexto, en el ámbito de la política económica, debe tomarse una decisión sobre la movilidad de capitales y sobre el tipo de cambio, lo cual 
conduce a ponderar las ventajas e inconvenientes de permitir la libre circulación de capitales o la libre fluctuación de la moneda. En todo caso, los autores argumentan a favor de que el euro y el yuan ganen peso frente al dólar en el diseño futuro de un sistema monetario internacional compatible con la «multipolarización» de la economía mundial. Quizás, en este mismo capítulo, hubiera sido deseable dedicar cierta atención a los instrumentos y los objetivos de la política comercial ya que, ante las medidas anunciadas por la Administración de Estados Unidos, ha resurgido el debate sobre el proteccionismo. Tampoco se dedica ningún espacio específico a otras políticas como la de competencia, de vivienda, protección social o medioambiental. No es un libro que pretenda un repaso exhaustivo de todas las políticas económicas.

En el capítulo ocho, dedicado a la política impositiva, adopta una perspectiva diferente. Mientras en los capítulos anteriores el enfoque era macroeconómico, este tiene una orientación microeconómica. Como instrumento de política económica se analiza su capacidad para asignar y distribuir sus recursos. En cambio, su utilización para gestionar la demanda agregada se supone incorporada a la política fiscal cuyo tratamiento, tal como se ha comentado, corresponde al capítulo cuatro. Aquí se observa una reducción del margen para el debate ya que asuntos tales como la traslación de los impuestos o las pérdidas irrecuperables de eficiencia que provocan tienen un tratamiento conocido $y$, desde el punto de vista puramente técnico o teórico, pueden resolverse sin dificultad. Otras cuestiones, como las relacionadas con el trade-off entre eficiencia y equidad o con la contribución que pueden hacer los impuestos para corregir los fallos del mercado, tienen una larga tradición en la literatura. No obstante, siguen existiendo preguntas que solo pueden responderse políticamente. Algunas de ellas son apuntadas en el texto y están relacionadas con el establecimiento de una fiscalidad mundial orientada a financiar los bienes públicos globales. En el caso de la Unión Europea sigue abierto el debate sobre la manera de financiar las políticas comunes y a nivel internacional han aparecido, en los últimos años, propuestas nuevas como, por ejemplo, la tasa mundial sobre la riqueza para combatir la desigualdad avalada por Piketty, o la creación de un club del clima, sugerido por Nordhaus, integrado por países comprometidos con la preservación del medioambiente que penalizarían las compras provenientes de aquellos Estados que opten por permanecer fuera del club.

El capítulo nueve contiene, además de definiciones y cuestiones elementales sobre el mercado de trabajo, una exposición de las nuevas aportaciones que, en este terreno, se han producido en las últimas décadas y que permiten mejorar el diseño de las políticas de empleo. No se cuestiona el objetivo del pleno empleo. Sin embargo, se afirma explícitamente que el análisis del mercado de trabajo debe mirar más allá de la tasa de desempleo para incorporar la calidad del empleo, la promoción profesional, y la equidad en las remuneraciones. Es destacable que el énfasis se traslade desde la tasa de desempleo a la tasa de no empleo, es decir, al porcentaje de personas en edad de trabajar que no tienen empleo (incluyendo a parados e inactivos), que sería una medida más adecuada para medir la capacidad de utilización de los recursos humanos. Este enfoque proporciona nuevos argumentos para decidir sobre los «arbitrajes irreductibles» entre incentivos y protección o, también aquí, entre eficacia y equidad. Las políticas se articularían a tres niveles: las políticas de empleo activas y pasivas, destinadas a aumentar la cantidad y mejorar la calidad del empleo; las políticas que afectan directamente a la demanda $u$ oferta de trabajo; y las que afectan al 
propio funcionamiento del mercado de trabajo. El capítulo concluye afirmando que la persistencia en las altas tasas de desempleo que padecen algunos países, lejos de ser una fatalidad tecnológica o económica, no es más que el reflejo de la incoherencia de las decisiones colectivas o de la falta de decisión de sus gobernantes. Tomemos nota.

En el capítulo diez, y último, se da otro giro y se aborda la política de crecimiento desde un punto de vista estructural, a largo plazo. Se repasan los modelos teóricos, desde los más elementales y clásicos, como los de Harrod-Domar o Solow-Swan, donde el progreso técnico es exógeno, hasta los que insisten en la importancia de la localización geográfica, como la revisión que realiza Krugman del modelo centro-periferia, o en las instituciones, propuesto por North, pasando por los modelos de desarrollo endógeno, de Romer o de
Aghion-Howitt. La teoría permite ordenar las políticas. Respecto al factor trabajo es posible estimular la participación en la población activa a través de reglamentaciones o estímulos fiscales o sociales. En cuanto al capital cabría actuar a través de incentivos a la acumulación de capital o mejorando la eficacia de los mercados de capitales. Y, a más largo plazo, las políticas públicas influyen sobre la productividad global a través de las instituciones, la inversión pública (educación, investigación, infraestructuras) y la regulación de los mercados. Ahora bien, se advierte que la calidad de las políticas de crecimiento está condicionada por la calidad de los procesos de decisión política.

No es un simple reclamo publicitario lo que se puede leer en la contraportada del libro. «Politique Économique se ha impuesto desde hace más de diez años como una referencia para comprender las políticas económicas actuales». Tampoco es exagerado lo que afirma Blanchard en el prefacio: "enseña a ser un buen economista, te inculca la actitud correcta y te proporciona la metodología correcta». Se fundamenta, tanto en los datos como en la teoría, para examinar las distintas políticas. La presentación es atractiva y asequible a muchos tipos de lectores ya que los desarrollos analíticos más complejos se han enmarcado en recuadros que pueden ser obviados por aquellos con menor preparación técnica, y, análogamente, permite a los más exigentes tener un acceso a explicaciones más rigurosas. Una traducción al español es necesaria para complementar y competir con los buenos manuales sobre política económica que ya están disponibles en nuestro idioma.

Beatriz Benítez-Aurioles 
